\title{
Erratum to: Effect of wetted graphene on the performance of Pt/PPy-graphene electrocatalyst for methanol electrooxidation in acid medium
}

\author{
Jun Zong • Qi Jin • Chengde Huang
}

Received: 15 January 2015 / Accepted: 16 January 2015 / Published online: 4 February 2015

(C) Springer-Verlag Berlin Heidelberg 2015

Erratum to: J Solid State Electrochem (2013) 17:1339-1348

DOI: 10.1007/s10008-012-1993-Z

The authors regret that the following Acknowledgement was incorrect. The corrected Acknowledgement is:

Financial support for this work was provided by Tianjin Natural Science Foundation (Grant No 11JCZDJC23800 and Grant No11JCYBJC07800).

The authors would like to apologise for any inconvenience caused. 